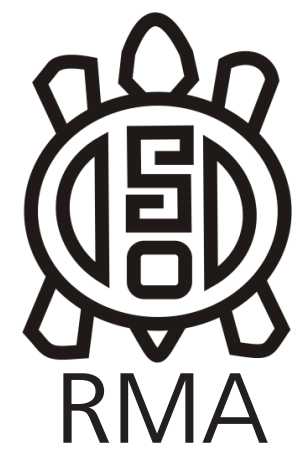

Arqueología

\title{
Cine documental y arqueología, una forma de contar el pasado
}

\author{
Documentary and archaeology. A way of telling the past \\ Natalia Mazzia*, Celeste Weitzel', Nora Flegenheimer*, Pablo \\ Dominguez** y Alejandro Mansilla**
}

*CONICET, Área Arqueología y Antropología, Museo de Ciencias Naturales de Necochea. E-mail: natymazzia@yahoo.com.ar; celweitzel@gmail.com; norafleg@ gmail.com; "*Productora Superfrascopuntocom; camaradocumental@gmail.com

\begin{abstract}
Resumen
En este trabajo presentamos los lineamientos generales y el estado de avance de un proyecto documental en el marco de la comunicación pública de la ciencia. La producción está destinada al público general, en formato audiovisual y a alumnos escolares. Para este último público el formato audiovisual está acompañado por un cuadernillo confeccionado por los investigadores responsables del contenido audiovisual. El documental, que se centra en la historia del sitio Cerro El Sombrero Cima, su entorno y la interpretación y el significado del sitio en la arqueología pampeana, es un capitulo de la serie "Ocupaciones Humanas, 10.000 años antes del presente" de la productora Superfrascopuntocom. El fin de la serie es contar interpretaciones científicas de una manera actualizada, familiar y atractiva para el público y generar conciencia sobre temas de arqueología que resultan significativos en la actualidad: cambio climático, las relaciones sociales, el otro cultural y la importancia de la protección del patrimonio. Aquí buscamos reflexionar acerca de la dinámica de la relación entre los documentalistas y los arqueólogos involucrados en el proyecto; una dinámica surgida del necesario intercambio de ideas, de las diferencias de objetivos y de las distintas formas de hacer que son propias de cada grupo de trabajo.
\end{abstract}

Palabras clave: Cine documental, Arqueología pública, Cerro El Sombrero Cima, Trabajo interdisciplinario

\begin{abstract}
The current paper presents the main guidelines and progress of an archaeological documentary which is part of a public archaeology project. The film is destined both for general public, in its television/internet format, and for school students; for this last audience the film can be used with printed material written by the archaeologists in charge of research. The documentary, which tells the story of Cerro El Sombrero Cima archaeological site, its setting, the archaeological interpretations and its meaning for past societies of the Pampean Region, is a chapter of the series "Ocupaciones Humanas, 10.000 años antes del presente" produced by Superfrascopuntocom. The goal of the series is to present scientific interpretations in a way that is modern and familiar for the audience and to create consciousness about important current archaeological topics, such as climate change, social relations, cultural differences and the importance of cultural heritage. The paper discusses the dynamics that emerged in the relationship between documentary producers and archaeologists, which involved the exchange of ideas, different goals and different "ways of doing" distinctive of each discipline.
\end{abstract}

Keywords: Documentary, Public archaeology, Cerro El Sombrero Cima, Interdisciplinary work.

El cine y la arqueología a menudo entrecruzan sus caminos. La ficción y el documental, incluso el documental ficcionado, resultan herramientas útiles al momento de comunicar conocimientos sobre el pasado y sobre nuestras variadas formas de estudiarlo. El punto de partida para este trabajo se sitúa precisamente en un cruce de caminos de arqueólogos y documentalistas. Como consecuencia comenzó a gestarse un documental sobre el sitio arqueológico Cerro El Sombrero Cima (Flegenheimer 2003), su entorno, la forma en que fue habitado y las diferentes maneras en las que es abordado su estudio. Este documental, aún en proceso de producción, no es un producto aislado. Se trata de un capítulo en la serie "Ocupaciones Humanas, 10.000 años antes del presente", ideada por la productora Superfrascopuntocom.

En esta oportunidad, nuestro objetivo es presentar junto a los lineamientos generales del proyecto y su estado de avance, un análisis de la dinámica de la relación surgida a partir del entrecruzamiento de las ideas y las formas de hacer de los arqueólogos y los productores documentalistas. 


\section{Caminos ya recorridos}

La arqueología en Argentina no ha sido ajena a este cruce de caminos. Cuando en la década de 1980 se estrenó la saga de Indiana Jones (de G. Lucas 1981, 1984, 1989), la práctica arqueológica, en su versión hollywoodense, fue ampliamente reconocida en la sociedad (Hiscock 2012). A pesar del estereotipo que presentaba, al interior de la disciplina, los arqueólogos también hicieron uso de su imagen: Indiana Jones fue proyectada por estudiantes de la carrera durante la realización de un congreso nacional en Buenos Aires en 1988 (IX CNAA); al tiempo que la imagen de otra ficción arqueológica (La Momia de K. Freund 1932) ilustraba la portada de la carpeta del congreso.

En la actualidad, son numerosas las producciones documentales desarrolladas en nuestro país que hacen foco en temas arqueológicos. El caso más notorio es el de la productora de contenidos documentales audiovisuales de CONICET (CONICET Documental) de ocho capítulos de la serie Tecnologías Originarias relatada por el Lic. Aschero y un unitario sobre El Shincal, protagonizado por el actor Boy Olmi. También con promoción de fondos públicos, en el marco del VII CARPA realizado en Rosario en el año 2014 se estrenó Rescate en la Llanura, 8000 años de huellas humanas, con la participación del Lic. Ávila y producido por el Ministerio de Innovación y Cultura de Santa Fe. En una línea similar de producción se estrenó en el año 2015 Lucía, una miniserie que desafía los relatos de nuestra identidad, de cuatro capítulos en formato de documental ficcionado realizados por PATRIMONIA (CONICET-INCUAPA) y FACSO Producciones, ambos pertenecientes a la Universidad Nacional del Centro de la Provincia de Buenos Aires (Chaparro et al. 2014). En el mismo año, en San Rafael, Mendoza, se presentó Al sur del río Diamante, con la participación del Dr. Neme. Se trata del primer capítulo de la serie en la que se enmarca el proyecto que presentamos en esta oportunidad. En años anteriores, fueron numerosas las producciones realizadas a partir de iniciativas públicas y privadas destinadas a dar a conocer en un formato audiovisual los resultados de investigaciones arqueológicas, los sitios, los materiales y el pasado que representan.

Durante las últimas tres décadas en la arqueología argentina se ha incrementado notablemente la atención puesta en cómo se produce la circulación social de los conocimientos sobre el pasado (Conforti y Endere 2012; Salerno 2013). La reflexión y el debate sobre la relación arqueología/comunidad se han instaurado explícita y definitivamente en la disciplina, al tiempo que los problemas teóricos y metodológicos relacionados con la comunicación pública de los conocimientos y el patrimonio forman parte de la agenda formal de los proyectos de investigación.

Cuando de comunicar se trata, la imágenes permiten establecer relaciones con un público mucho más amplio y heterogéneo. Diferentes estudios sobre el impacto de las representaciones visuales y sobre la formación de imágenes sobre el pasado y su estudio dan cuenta de su gran poder comunicador (Molineaux 1997; Moser 1998; Miotti 2003; Alarcón et al. 2012, entre otros). En este sentido, las producciones audiovisuales cobran aún más fuerza al momento de definir dispositivos de comunicación. El cine documental, al presentar imágenes y sonidos permite hablar sobre el pasado al tiempo que, en cierta forma, le permite hablar al pasado (Cowie 2011) a partir de los objetos y los lugares arqueológicos. Independientemente del debate que pueda generarse sobre su calidad de no-ficción o ficción, el objetivo y el papel del documental es generar conocimiento, explicar, enseñar sobre el tema tratado (Ghatak 1987; Ramos Sainz 2006). En este aspecto se subraya la importancia del género documental para la comunicación sobre pasado y la relevancia que ha alcanzado en los últimos tiempos, no sólo para la enseñanza sino también para la puesta en valor del patrimonio (Ramos Sainz 2006).

Las filmaciones realizadas por arqueólogos, o en las que los arqueólogos tienen un papel importante, pueden ser caracterizadas según Morgan (2014) en función de cuatro géneros: enunciativo; testimonial directo, impresionista y fenomenológico. El documental que presentamos correspondería al primer género, que incluye las filmaciones destinadas a educación y al público general. Estas realizaciones audiovisuales son producidas por documentalistas/cineastas y arqueólogos y se utilizan diversos recursos cinematográficos para que un tema de arqueología pueda presentarse como una historia coherente. Son producciones cuyo fin es alcanzar audiencias diversas y heterogéneas, en las que se les permite a los arqueólogos contar sus propias interpretaciones e incluyen entrevistas, relatos y tomas del paisaje (Morgan 2014). Se presenta como un formato que da lugar a una mirada actualizada y descontracturada de la ciencia. Consideramos que por sus requerimientos técnicos y teóricos, la realización audiovisual en arqueología exige un trabajo en colaboración, el cruce de caminos entre arqueólogos y documentalistas.

El trabajo interdisciplinario hoy en día resulta una práctica común en la investigación arqueológica. De acuerdo con los temas estudiados, la interacción con historiadores, químicos, físicos, geólogos o paleontólogos (por nombrar algunos) se torna habitual y cuenta ya con cierta historia. Su éxito depende de que puedan establecerse de forma clara, y desde el comienzo de la relación, los términos y conceptos usados, las posibilidades y limitaciones técnicas y las escalas de análisis. Resulta indispensable llegar a acuerdos sobre los objetivos del proyecto, sus contenidos y cómo serán enfocados los temas a tratar en forma conjunta (Zárate 1997). La relación de colaboración con comunicadores sociales, si bien es cada vez más frecuente, se presenta aún con un menor trayecto 
recorrido. En particular, en nuestro caso no sólo hubo que acordar la agenda de contenidos, también fue necesario compatibilizar dos formas de hacer muy diferentes. Los tiempos destinados a las distintas tareas, las formas de comunicación entre quienes trabajan, la inserción final del producto y las fuentes de financiamiento son pensados y puestos en práctica de maneras diferentes, todo ello requiere gran comprensión del punto de vista del otro. Resulta, por supuesto, un ejercicio interesante.

Un antecedente local para este trabajo, también con el sitio Cerro El Sombrero Cima como protagonista, fue un video documental realizado en formato VHS en el año 1995. En aquella oportunidad se trabajó con financiación de la Fundación Antorchas y de una institución local de Necochea, la Fundación Educacional de la Usina Popular cooperativa Sebastián de María. Dirigida a un público general, la realización presentaba entrevistas a Nora Flegenheimer y Marcelo Zárate quienes explicaban sus interpretaciones sobre el sitio y mostraban los materiales conocidos hasta el momento. Este documental formó parte de las continuas tareas de comunicación generadas desde el Área de Arqueología y Antropología, por aquel entonces, vinculadas a la labor del Museo de Ciencias Naturales de Lobería con Gesué Noseda como su principal impulsor.

\section{Sobre los encuentros y los proyectos}

La propuesta original surgió de manera informal a partir de un correo electrónico de los documentalistas dirigido a una de las arqueólogas del equipo. Recién llegados del sur de Mendoza, donde habían tenido un primer acercamiento al mundo de la arqueología, buscaban contactos para desarrollar un proyecto en la provincia de Buenos Aires. La base de este proyecto era generar material audiovisual con fines educativos y de comunicación científica. En los primeros intercambios predominó la curiosidad por sobre los acuerdos entre ambas partes: los realizadores no quedaban convencidos con el contenido propuesto por las arqueólogas y las arqueólogas no terminaban de entender los intereses del equipo de filmación. La propuesta narrativa audiovisual buscaba contar los últimos 12.000 años a partir de un sitio arqueológico, pero en el encuentro los documentalistas conocieron la historia del Cerro El Sombrero y sus materiales arqueológicos que permitían abordar sólo los 2.000 años más antiguos. Entonces, en parte seducidos por las puntas cola de pescado y lo que éstas permitían contar visualmente, decidieron adaptar la narrativa a la temporalidad que ofrecía la investigación arqueológica.

Además, en un comienzo el proyecto documental se basaba en una idea general de visibilizar los resultados del trabajo arqueológico a partir de un relato de la historia cultural y ambiental de la región. No obstante, el equipo de investigación tenía en agenda un temario propio que apuntaba a remarcar la profundidad temporal del poblamiento regional y a deconstruir la visión, frecuentemente arraigada en el sentido común, de los primeros pobladores pampeanos inmersos en un mundo salvaje y exótico. Así, surgió entre los cineastas una mirada diferente a la que traían de la experiencia en Mendoza y un reacomodamiento de ideas para poder contar sobre estas sociedades tempranas que ya se encontraban bien establecidas en la zona hace más de 10.000 años.

Las principales dudas pudieron disiparse, entonces, con un primer encuentro cara a cara, cuando los intereses y los caminos recorridos por cada grupo se hicieron explícitos. Aquella primera reunión sucedió en Necochea, en el espacio de trabajo del Área de Arqueología y Antropología. Allí se registró una primera entrevista que se transformó en el material de base para el guión del documental, sobre el que aún se continúa trabajando. También se realizaron tomas de los materiales arqueológicos más significativos hallados en el Cerro El Sombrero y se registraron escenas de arqueología experimental, principalmente de talla lítica. La entrevista, los objetos arqueológicos y los experimentos fueron el primer canal de acercamiento que permitió materializar ideas y marcar el camino a seguir. Es decir, en este encuentro se cimentaron las bases del proyecto y se comenzó el trabajo de compatibilizar las propuestas sobre contenidos y, especialmente, las formas de hacer propios de ambas disciplinas. Los principales acuerdos llegaron, entonces, con el diálogo mano a mano, pero mediado por los objetos arqueológicos; conocer en persona a los objetos hallados en el sitio generó nuevas ideas en los cineastas.

Como mencionamos anteriormente, este documental fue pensado como un capítulo dentro de una serie. En formato audiovisual para televisión e internet, la serie está destinada a un público general con una duración aproximada de no más de media hora. En tanto que en formato "hora cátedra" el material estará orientado para su uso en espacios escolares, con la posibilidad de realizar cortes cuando el docente a cargo lo considere necesario para profundizar los temas. En este ámbito, el audiovisual será acompañado por un cuadernillo confeccionado por el equipo de investigación responsable del contenido del documental. Entonces, la actividad propuesta para desarrollar durante una hora cátedra consiste en la entrega de cuadernillos, la proyección de la película y resolución de preguntas con formato multiple choice. El objetivo de la presentación en el espacio escolar es comunicar conocimiento sobre el pasado. Las preguntas se ofrecen como una opción para los docentes, en caso de que las consideren de utilidad, para realizar un cierre de la actividad mediante preguntas generales generadas a partir de los contenidos del documental. De acuerdo con el proyecto propuesto, la serie presentará un capítulo por cada provincia de nuestro país con el objetivo de contar interpretaciones científicas de manera actualizada que resulten familiares 
y atractivas al público. Asimismo, busca generar debate y reflexión sobre temas surgidos de la arqueología y significativos para la vida actual, tales como los cambios climáticos, las relaciones sociales y el reconocimiento y la valoración del otro cultural.

El primer capítulo de esta serie se estrenó, en un aula del colegio José Mármol, en Real del Padre, San Rafael, Mendoza, en el marco de las actividades de la Semana Nacional de la Ciencia y la Tecnología, en julio del 2015 con estudiantes de sexto grado. Al sur del rio Diamante tiene una duración de 31 minutos y cuenta, a partir de la presentación del Dr. Neme, un recorrido del pasado arqueológico del sur mendocino basado en las investigaciones realizadas en el sitio Cueva del Indio (Neme y Gil 2012), ubicado en las proximidades de la ciudad de San Rafael.

\section{Cerro El Sombrero Cima en versión audiovisual}

El documental sobre Cerro El Sombrero Cima cuenta el pasado de los primeros pobladores pampeanos a partir de las investigaciones en un sitio asignado a las ocupaciones humanas en la pampa bonaerense ocurridas durante la transición Pleistoceno/Holoceno y el Holoceno Temprano (Flegenheimer 2003). Es en este marco temporal en el cual se desarrolla el relato.

En sus diferentes capítulos, la serie busca dar a conocer los últimos 10.000 años de historia, con un marcado énfasis en aspectos paleoambientales y en los cambios climáticos acontecidos hace 20.000 años. En ese devenir de cambios, la historia cultural que se presenta comienza con el poblamiento de América para centrarse, en este caso, en un sector de las sierras de Tandilia, en la provincia de Buenos Aires. La llegada de los primeros pobladores al continente americano, los lugares habitados, los caminos que recorrieron en el nuevo territorio son temas de continuo debate en el seno de la comunidad arqueológica y que también producen cierta atracción fuera de los espacios académicos.

Cerro El Sombrero Cima es un sitio a cielo abierto ubicado en toda la extensión de la cumbre más alta del sector centro oriental de Tandilia (Figura 1). Las investigaciones sistemáticas en el sitio comenzaron hace más de 30 años. La caracterización de la manera en que este sitio fue habitado por los pobladores tempranos se construyó a partir de una multiplicidad de análisis enfocados principalmente en la cultura material y la espacialidad. La cultura material del sitio fue abordada desde el estudio de la bifacialidad (Flegenheimer 1991), los artefactos manufacturados por picado, abrasión y pulido (Flegenheimer et al. 2013), las puntas cola de pescado (Flegenheimer et al. 2010; Weitzel et al. 2014), los desechos de manufactura (Flegenheimer y Cattáneo 2013), las materias primas empleadas, las modalidades de su traslado (Flegenheimer et al. 2003; Bayón et al.

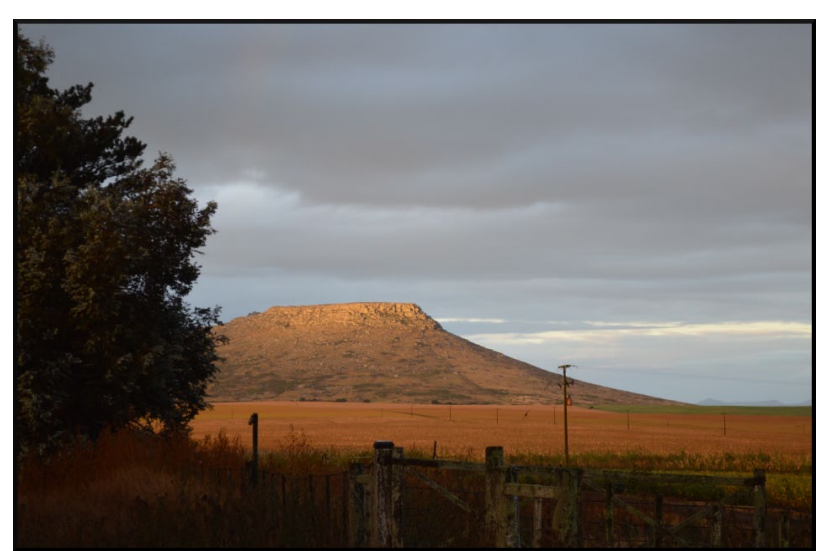

Figura 1. Vista del cerro El Sombrero. El sitio ocupa toda la superficie de la cima plana.

Figure 1. View of Cerro El Sombrero. The site occupies the entire surface of the flat top.

2006), el valor simbólico de las rocas elegidas para la talla (Flegenheimer y Bayón 1999), las fracturas de los instrumentos (Weitzel 2010) y el uso de los objetos por medio de análisis microscópicos (Leipus 2012) y de sustancias grasas conservadas en sus superficies y microfracturas (Mazzia y Flegenheimer 2015). Los análisis espaciales se han enfocado en cuestiones tales como el emplazamiento del sitio, su extensión y densidad artefactual, la accesibilidad, la visibilidad y la visibilización del sitio (Mazzia 2010/2011; Flegenheimer y Mazzia 2013).

A partir de la integración de todos estos estudios el sitio es interpretado como un lugar significativo en el paisaje de los cazadores recolectores tempranos que habitaron la pampa bonaerense.

En el documental, a partir de una estrategia de tipo zoom (visual y narrativa) se presenta entonces el poblamiento de Sudamérica, el de la Región Pampeana, hasta acercarse a las primeras evidencias de la presencia humana en la sierras de Tandilia, donde se ubica el sitio.

La trama del relato introduce al espectador en los modos de vida de estos primeros pobladores, su organización social, la forma en que habitaron el espacio, la significación de los lugares y la construcción del paisaje. Al presentar algunos detalles sobre su vida cotidiana, se particulariza su modo de subsistencia, los recursos utilizados y las variadas estrategias para conseguirlos. Cada uno de estos temas es expuesto junto a las metodologías utilizadas en el estudio de las diferentes evidencias encontradas en el sitio.

La historia presentada en esta realización audiovisual tiene como soporte imágenes y escenas tomadas durante el trabajo de campo, entrevistas, animaciones, recursos de dibujos, toma aérea, música original, locución, efectos sonoros y gráfica. La grabación fue realizada en formato full HD (1920 x 1080) con cámaras DSLR y GoPro.

La caracterización del sitio y el pasado que representa son contados por los investigadores del Área Arqueología 
y Antropología en diferentes entrevistas. Dado que los contextos arqueológicos de la microrregión serrana son predominantemente líticos, con una escasa o nula preservación de macro restos orgánicos, la tecnología lítica y su estudio es uno de los temas centrales y recurrentes en la presentación. Las entrevistas incluyen relatos sobre las canteras de piedra indígenas (Colombo 2013), las preferencias de los primeros pobladores por las piedras coloreadas (Flegenheimer y Bayón 1999; Colombo y Flegenheimer 2013) y las relaciones con lugares distantes evidenciadas en estos materiales líticos (Flegenheimer et al. 2003). También se trata el concepto de lugar (Mazzia 2013), el sitio Cerro El Sombrero Cima como lugar significativo para las sociedades pampeanas (Flegenheimer y Mazzia 2013) y los estudios de detalle que se están realizando en los materiales del sitio como los análisis de sustancias grasas (Mazzia y Flegenheimer 2015) y de patrones de fractura (Weitzel 2010; Weitzel et al. 2014).

Junto con las entrevistas, los registros de escenas con arqueología experimental son centrales en la narración presentada. La talla lítica y la utilización de réplicas de instrumentos y de armas experimentales resulta un recurso interesante en la comunicación visual propuesta en el documental. Las imágenes registradas en el entorno serrano, durante la llegada al sitio y del desarrollo de una excavación realizada en la cima del cerro son el marco en el que se presentan algunos de los materiales y temas más significativos de este sitio, como las puntas cola de pescado, las rocas procedentes de largas distancias, las miniaturas y los colores de los artefactos líticos. Desde los recursos técnicos se buscó que cada una de las tomas, sean planos abiertos o primerísimos primeros planos, mostraran movimiento. El objetivo de evitar planos estáticos y privilegiar el movimiento en las tomas fue resaltar la continuidad de la historia.

\section{Dinámica de la relación entre los equipos}

En las diferentes tareas involucradas en el proceso de realización del documental sobre el Cerro El Sombrero participaron los investigadores (CONICET), estudiantes y colaboradores nucleados en el Área Arqueología y Antropología del Museo de Ciencias Naturales de la Municipalidad de Necochea y los integrantes de la productora Superfrascopuntocom. Esta última incluye, además de a los realizadores y guionistas que encabezan el proyecto, a colaboradores que trabajan en la edición, musicalización y locución del producto. Se trata de un grupo heterogéneo que trabaja en forma colectiva con el objetivo de generar un nuevo material útil en la comunicación de conocimientos sobre la vida social en el pasado pampeano.

Como mencionamos anteriormente, el guión comenzó a escribirse a partir de la desgrabación de la primera entrevista. El temario que finalmente quedó incluido en ese registro fue producto de negociaciones, desacuerdos y acuerdos. La puesta en común de los temas que los documentalistas buscaban mostrar y aquellos que el grupo de investigación quería subrayar en la historia fue un proceso que continuó aún después de realizado el primer encuentro y que se extiende hasta el proceso de edición. El material registrado en aquella entrevista fue usado para delinear la escaleta del documental. Allí se marcaron los temas que serían remarcados durante el relato con intervenciones especiales de los diferentes arqueólogos mediante nuevas entrevistas. Los principales inconvenientes surgieron en relación con la extensión de los textos que serían la base del material presentado en las entrevistas. Los textos producidos por los arqueólogos resultaban demasiado extensos, y no siempre atractivos, para los tiempos y el ritmo del documental. La experiencia de los cineastas en el tema fue la que delineó y acomodó el formato de sus contenidos.

En el laboratorio, los objetos arqueológicos mediaron el diálogo. Nuevamente, surgían diferencias respecto a las preferencias al momento de elegir qué mostrar, qué

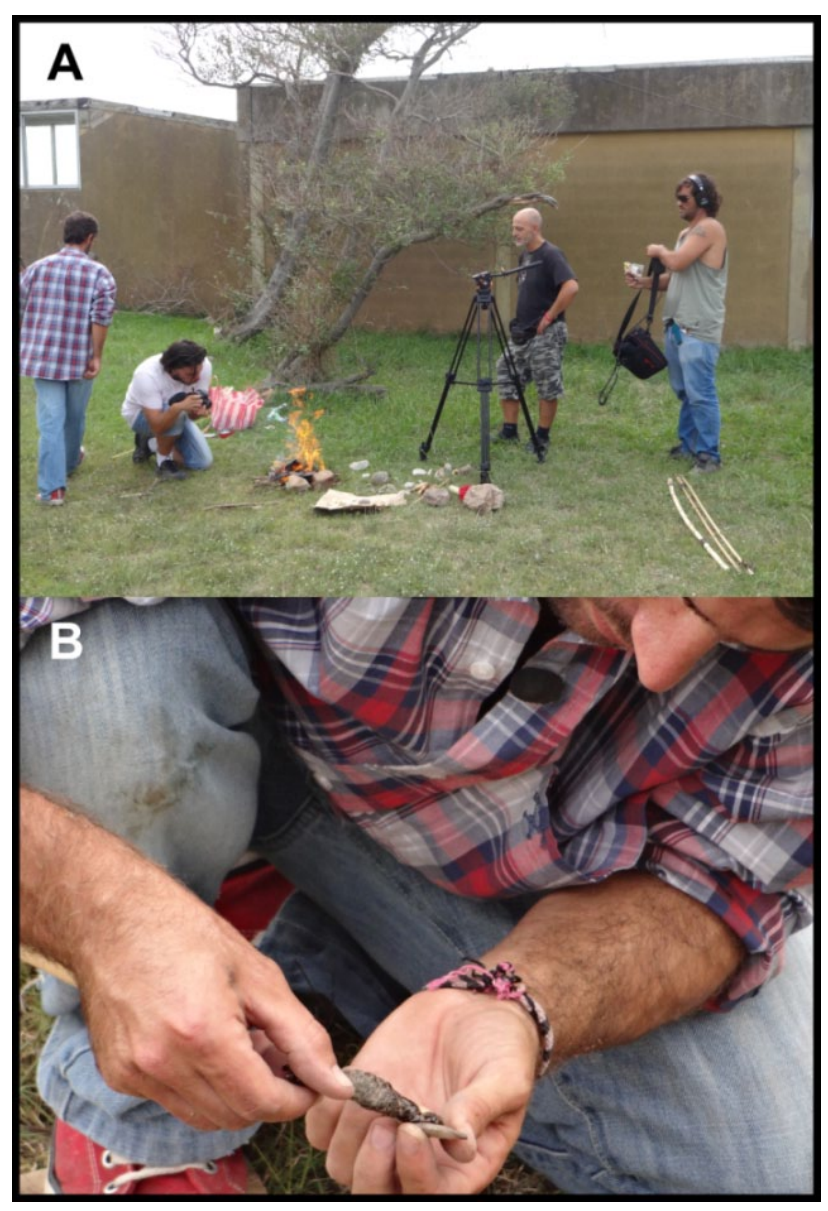

Figura 2. Registros de arqueología experimental. Filmación (A) y detalle (B) de la confección de puntas de proyectil.

Figure 2. Records of experimental archeology. Filming $(A)$ and detail (B) of the construction of projectile points. 
recorte hacer dentro del conjunto. Para los arqueólogos, los objetos cuentan historias, identidades, relaciones, distancias. Nos remiten a la materialidad de la vida social en el pasado (Miller 1987; 2005; Pels et al. 2002; Meskel 2005). Los documentalistas resaltaban formas, colores, brillos, texturas, todo enlazado con las interpretaciones escuchadas. Los planos de detalle y los contraluces fueron recursos usados para realzar visualmente la historia presente en esos objetos. Se buscó, además, evitar imágenes estáticas incorporando movimientos de cámara y efectos sonoros.

Los registros de arqueología experimental (Figura 2) fueron quizás los más sencillos de acordar. La talla lítica, en esta oportunidad a cargo del Dr. Colombo, permitió hacer visible y palpable el proceso de manufactura de los instrumentos de piedra y su utilidad práctica. No sólo se realizaron escenas de talla, se mostró la preparación de un astil con cuero y mástic para enmangar puntas de proyectil que, luego, fueron lanzadas con un propulsor. La experimentación en arqueología ejerce un importante impacto visual al momento de comunicar, permite observar a los objetos en el contexto de una práctica, involucrando los gestos y los movimientos necesarios en su uso (Colombo y Vecchi 2013).

La organización del trabajo de campo requirió del despliegue de una logística particular, diferente a la acostumbrada en las investigaciones arqueológicas. Un primer escollo se presentó al definir la cantidad de participantes, que resultó ser el doble de la que generalmente sube al cerro durante una excavación. En cuanto a aspectos formales, los permisos en los campos a los que debíamos entrar debieron ser especiales y cargados de explicaciones. En cuestiones más prácticas, el equipamiento propio de un grupo de documentalistas requiere de ciertas condiciones mínimas en cuanto a protección, traslado y, principalmente, disponibilidad de energía para poder contar con computadora portátil y baterías para las cámaras y el equipo de sonido. Por todo esto, los preparativos implicaron tiempos y una planificación atípica. En este caso, el equipo arqueológico

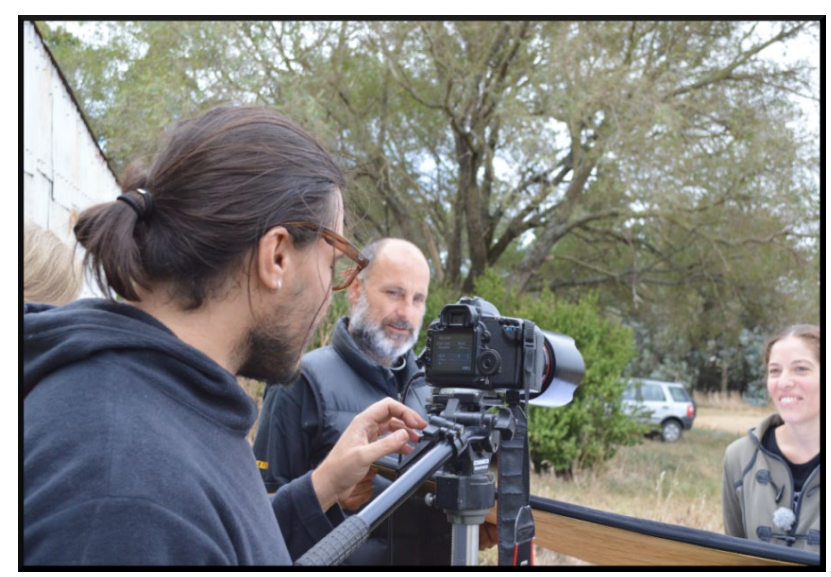

Figura 3. Realización de entrevistas durante el trabajo de campo.

Figure 3. Conducting interviews during the fieldwork.

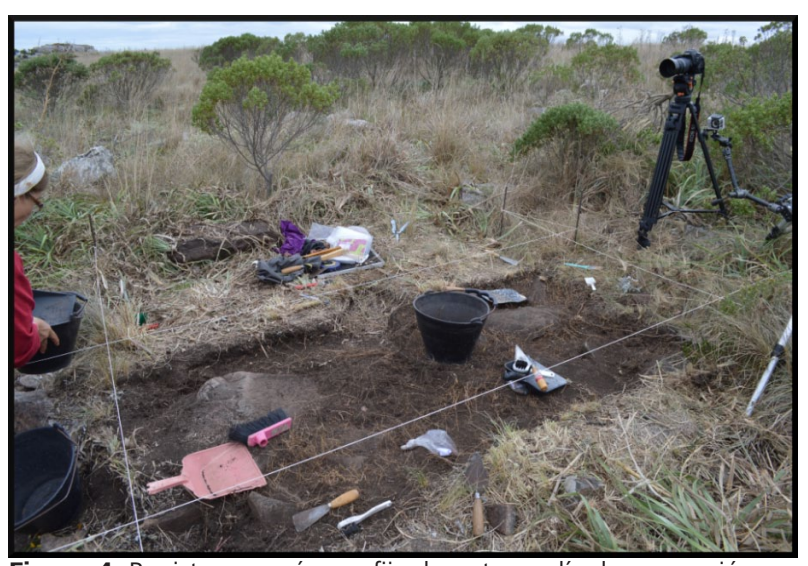

Figura 4. Registro con cámara fija durante un día de excavación.

Figure 4. Recording with a fixed camera during a day of excavation.

actuó de anfitrión, con un profundo conocimiento del lugar y sus posibilidades. El desafío mayor cayó sobre los hombros de quienes llevaban las cámaras. La instancia de preproducción, incluso de producción, resultaron complejas para los cineastas al no conocer en persona el sitio ni su entorno, disponiendo de pocos días para adaptarse y dar lugar a la realización.

El encuentro de los dos equipos completos, cada uno con sus expectativas, sus ritmos y sus formas de hacer las cosas, se produjo finalmente en el campo, con el cerro El Sombrero como escenario. Allí, se filmaron entrevistas a diferentes miembros del grupo de arqueología sobre los temas particulares que se presentan en el documental (Figura 3), se registró la excavación de dos cuadrículas (Figura 4) y se realizaron tomas del entorno. El ambiente de trabajo, la convivencia y la comida colaboraron con la creatividad y lucidez necesarias para captar con la cámara todas aquellas imágenes con las que se busca movilizar y atrapar la atención de los futuros espectadores.

En el marco de la narrativa visual, a partir de la excavación y las acciones vinculadas a la misma surgieron tres líneas de acción: una en la cuadrícula, otra en la zaranda y una última que vinculaba a ambas. Para la excavación de la cuadrícula el planteo fue de tres paredes ubicando al personaje protagonista en el centro y al resto mitad por lado. La cámara fija se ubicó en la cuarta pared. En el caso de la zaranda el planteo de cámara fue de dos frentes, uno en el que se veía de fondo la excavación y otro en el que el fondo lo constituía la cima misma del cerro. Para la vinculación entre ambos espacios el planteo de cámara también fue de dos frentes, uno desde la cuadrícula y otro desde la zaranda. En cada caso, se utilizaron como recursos planos de ubicación, planos cortos y detalles de las acciones. Dado que la excavación fue la protagonista principal de la trama, su registro se realizó de diferentes maneras y utilizando intervalómetros que permitieran cubrir lo sucedido a lo largo de todo el día.

Cabe destacar que para la dinámica del trabajo en 
conjunto, el tiempo transcurrido en el cerro y las tareas desarrolladas en el campo contribuyeron a la conciliación de visiones y a la definición del proyecto.

\section{Palabras finales}

El trabajo interdisciplinario tiene profundos antecedentes en la arqueología argentina. Como producto de las frecuentes interacciones con especialistas de otros campos, la práctica arqueológica se ha nutrido de conceptos, metodologías, procedimientos y datos incorporados como propios. La interdisciplinariedad implica la creación de vínculos entre diferentes puntos de vista, formas de hacer y de pensar que potencian cada una de las experiencias desarrolladas (Boehm 2000). El equipo del Área de Arqueología y Antropología ha trabajado repetidamente en colaboración con geólogos, cuaternaristas, especialistas en sensores remotos, químicos y físicos; pero es la primera oportunidad en la que surge un proyecto conjunto con realizadores documentalistas. En un momento en el que la comunicación pública del conocimiento sobre el pasado y el patrimonio arqueológico son parte de la agenda formal de los proyectos de investigación, la búsqueda de dispositivos más atractivos para un público heterogéneo resulta central. En el caso de una propuesta audiovisual, resulta clave generar un producto que logre captar la atención de los espectadores hasta el final. Para ello, es necesario estar a tono con los tiempos, el ritmo y las pausas que proponen los productos actuales tanto en la televisión como en la red.

Consideramos que el cruce de caminos entre arqueólogos y comunicadores sociales, documentalistas, escritores y artistas plásticos (por nombrar algunos) va a ser cada vez más frecuente. Este tipo de trabajo compartido enriquece profundamente las representaciones sobre la vida cotidiana de las personas del pasado, sus lugares y objetos. Además, puede facilitar y hacer más amena la tarea de comunicación de la ciencia y su consecuente valorización de nuestro pasado y nuestro patrimonio.

Necochea, 21 de Febrero de 2017

\section{Agradecimientos}

Queremos agradecer a todos aquellos que colaboraron con el proyecto de esta realización audiovisual: por el Área de Arqueología y Antropología a Águeda Caro Petersen, Mariano Colombo, Valeria Elichiry, Franco Pazzi, Marilina Martucci, Pamela García Laborde, Josefina Motti, Ivan Quattrini, Miguel Fernández Long y por Superfrascopuntocom a Raúl Taibo, Marcos Gonzalez Gava, Gonzalo Clavel, Alejandro del Campo, Cristian Gonzalez Larssen, Andrés Reddy, Aníbal Girbal, Andrés de Marchi, Maximiliano Gonzalez Gava y Alejandro Parvis. A Virgina Salerno un especial agradecimiento por invitarnos al simposio en el que fue presentado una versión de este trabajo. Finalmente, al personal del establecimiento Santa Marta y, muy especialmente, a Lucio Bernazza por darnos un lugar en su campo y a Rodrigo Costa Angrizani por ayudarnos con el portugués en una versión previa del manuscrito. Este trabajo se enmarca en los proyectos CONICET-PIP 112 -201101-00177 y PICT 2014-3054.

\section{Bibliografía}

Alarcón, E., L. Colomer, A. García Luque, P. González Marcén, C. Masvidal, M. Picazo, C. Rísquez, M. Sánchez Romero y B. Soler. 2012. Los trabajos de las mujeres y el lenguaje de los objetos. Recuperación de la cultura material femenina como herramientas de transmisión de valores. Memorias del proyecto I+D+I 2007. Exp. 002/07, Instituto de la Mujer, Barcelona.

Bayón, C., N. Flegenheimer y A. Pupio. 2006. Planes sociales en el abastecimiento y traslado de roca en la Pampa bonaerense en el Holoceno Temprano y Tardío. Relaciones de la Sociedad Argentina de Antropología 31: 19-27.

Boehm, B. 2000. El péndulo interdisciplinario, arqueología, etnohistoria y anexas. Relaciones. Estudios de historia y sociedad, XXI(87): 120-155

Chaparro, M. G., M. E. Conforti, M. C. Prandini, M. V. Giacomasso y P. E. Degele. 2014. Arqueología y comunicación: explorando nuevas estrategias y formatos de comunicación pública de la ciencia. Trabajo presentado en VII Congreso de Arqueología de la Región Pampeana Argentina, Rosario, Argentina.

Colombo, M. 2013. “Los cazadores recolectores pampeanos y sus rocas. La obtención de materias primas líticas vista desde las canteras arqueológicas del centro de Tandilia". Facultad de Ciencias Naturales y Museo, Universidad Nacional de La Plata, Argentina, 507 páginas. Tesis de Doctorado. http://sedici.unlp. edu.ar/handle/10915/29170.

Colombo, M., N. Flegenheimer. 2013. La elección de rocas de colores por los pobladores tempranos de las sierras de Lobería (Buenos Aires, Argentina). Nuevas consideraciones desde las canteras. Boletín del Museo Chileno de Arte Precolombino 18(1): 125-137.

Colombo, M., R. Vecchi. 2013. Saber hacer, saber usar: reflexiones a partir de una experiencia didáctica con armas prehispánicas. Revista del Museo de La Plata, Sección Antropología 13(87): 199-216.

Conforti, M. E., M. L. Endere. 2012. La imagen de la arqueología y el patrimonio arqueológico en los medios de comunicación. Un análisis sobre la prensa gráfica local. Antípoda 14: 163-184.

Cowie, E. 2011. Introduction: The Spectacle of Actuality and the Desire for Reality. En; E. Cowie (ed.), Recording Reality, Desiring the Real, pp 1-18. University of Minnesota Press, Minneapolis.

Flegenheimer, N. 1991. Bifacialidad y piedra pulida en sitios pampeanos tempranos. Shincal 3(2): 64-78. 
Flegenheimer, N. 2003. Cerro El Sombrero: A Locality with a View. En: L. Miotti; M. Salemme y N. Flegenheimer (eds.), Where the South Winds Blow. Ancient Evidence of Paleo South Americans, pp 51-53. Centre for the Study of the First Americans, A\&M University Press, Texas.

Flegenheimer, N., C. Bayón. 1999. Abastecimiento de rocas en sitios pampeanos tempranos: recolectando colores. En: C. Aschero, A. Korstanje y P. Vuoto (Eds.), En los tres reinos: prácticas de recolección en el Cono Sur de América, pp. 95107. Ediciones Magna Publicaciones, Tucumán.

Flegenheimer, N., R. Cattáneo. 2013. Análisis comparativo de desechos de talla en contextos del Pleistoceno Final/Holoceno Temprano de Chile y Argentina. Magallania 41(1): 171-192.

Flegenheimer, N., N. Mazzia. 2013. Cerro El Sombrero Cima, un lugar particular para los pobladores tempranos. Revista del Museo de La Plata, Sección Antropología 13 (87): 217-232.

Flegenheimer, N., J. G. Martínez y M. Colombo. 2010. Una Experiencia de Lanzamiento de puntas cola de pescado. En: M. Berón, L. Luna, M. Bonomo, C. Montalvo, C. Aranda and M. Carrera Aizpitarte (Eds.), Mamül Mapu: Pasado y Presente desde la Arqueología Pampeana. pp. 215-36. Editorial Libros del Espinillo, Buenos Aires.

Flegenheimer, N., N. Mazzia y M. del P. Babot. 2013. Estudios de detalle sobre una piedra discoidal pampeana. Intersecciones en Antropología 14: 499-506.

Flegenheimer, N., C. Bayón, M. Valente, J. Baeza y J. Femenías. 2003. Long Distance Tool Stone Transport in the Argentine Pampas. Quaternary International 109-110: 49-64.

Ghatak, R. 1987. Cinema and I. Ritwik Memorial Trust, Calcuta.

Hiscock, P. 2012. Cinema, Supernatural Archaeology and the Hidden Human Past. Numen 59: 156-177.

Leipus, M. 2010. El uso de los conjuntos líticos tempranos de Tandilia (Región Pampeana, Argentina): evidencias a partir del análisis funcional de base microscópica. Resúmenes del $\mathrm{V}$ Simposio Internacional El Hombre Temprano en América, 8081. La Plata, Argentina.

Mazzia, N. 2010-2011. “Lugares y paisajes de cazadoresrecolectores en la pampa bonaerense: cambios y continuidades durante el Pleistoceno final-Holoceno". Facultad de Ciencias Naturales y Museo, Universidad Nacional de La Plata, Argentina, 491 páginas. Tesis de Doctorado.

Mazzia, N. 2013. Lugares y paisajes de cazadores recolectores pampeanos: una propuesta para su estudio. Revista del Museo de La Plata, Sección Antropología 13 (87): 233-253.

Mazzia, N., N. Flegenheimer. 2014. Detailed fatty acids analysis on lithic tools, Cerro El Sombrero Cima, Argentina. Quaternary
International 363:96-106. doi: 10.1016/j.quaint.2014.04.027.

Meskell, L. 2005. Archaeologies of Materiality. Blackwell, Oxford.

Miller, D.1987. Material Culture and Mass Consumption. Blackwell, Oxford.

Miller, D. 2005. Afterwords. En L. Meskell (Ed.), Archaeologies of Materiality, pp 212-219. Blackwell, Oxford.

Miotti, L. L. 2003. Colonizar, migrar, poblar: tres conceptos que evocan las imágenes de la apropiación humana del Nuevo Mundo. En: R. Curtoni y Ma. Luz Endere (eds.), Análisis Interpretación y Gestión en la Arqueología Sudamericana. pp 91- 120. INCUAPA, UNICEN, Olavarría.

Molineaux, B. (editor). 1997. The Cultural Life of Images: Visual Representation of Archaeology. Routledge, Londres.

Morgan, C. 2014. Archaeology and the Moving Image. Public Archaeology 13(4): 323-344. doi: 10.1179/1465518715Z.00 000000077.

Moser, S. 1998. Ancestral Images: The Iconography of Human Origins. Sutton: Stroud.

Neme, G., A. Gil. 2012. El registro arqueológico del sur de Mendoza en perspectiva biogeográfica. En: G. Neme y A. Gil (Comps.), Paleoecología humana en el sur de Mendoza: perspectivas arqueológicas, pp. 255-280. Sociedad Argentina de Antropología, Buenos Aires.

Pels, D., K. Hetherington y F. Vandenberghe. 2002. The Status of the Object: Performances, Mediations, and Techniques. Theory Culture Society 19(5/6): 1-21.

Ramos Sainz, M. L. 2006. Cine y arqueología: instrumento de difusión y análisis. En: J. M. Iglesias Gil (Ed.), Cursos Monográficos sobre el Patrimonio Histórico, pp 19-30. Universidad de Cantabria, Ayuntamiento de Reinosa.

Salerno, V. 2013. Trabajo arqueológico y representaciones del pasado en la provincia de Buenos Aires. Editorial de la Facultad de Filosofía y Letras, UBA, Buenos Aires.

Weitzel, C. 2010. "El estudio de los artefactos formatizados fracturados. Contribución a la comprensión del registro arqueológico y la actividad humana". Facultad de Filosofía y Letras, Universidad de Buenos Aires, Argentina, 425 páginas. Tesis de Doctorado. Weitzel, C., N. Flegenheimer, J. Martínez y M. Colombo. 2014. Breakage patterns on fishtail projectile points: experimental and archaeological cases. Ethnoarchaeology 6(2): 81-102.

Zárate, M. 1997. Late Pleistocene Geoarchaeology of the Southern Pampas, Buenos Aires Province, Argentina. Anthropologie 35(2): 197-205. 